\title{
Control and Operation of a New 8/6-Pole Doubly Salient Permanent-Magnet Motor Drive
}

\author{
Ming Cheng, Senior Member, IEEE, K. T. Chau, Member, IEEE, C. C. Chan, Fellow, IEEE, and Qiang Sun
}

\begin{abstract}
This paper proposes a new 8/6-pole doubly salient permanent-magnet (DSPM) motor drive, which offers the advantages of higher power density, higher efficiency, and wider speed range. The corresponding control and operation of the motor drive are presented. A variable proportional-integral (PI) controller combined with bang-bang control for the DSPM motor drive is developed. Two operation modes, namely, four-phase and two-phase operation modes, are proposed for the 8/6-pole DSPM motor drive. The drive system is implemented and tested. The results show that the developed control scheme can operate the DSPM motor properly, and the DSPM motor drive offers high efficiency over wide power range and good dynamic performance. Furthermore, the two-phase operation mode of the 8/6-pole DSPM motor offers the possibility of eliminating the torque ripple of the motor drive.
\end{abstract}

Index Terms-Control strategy, doubly salient (DS) motor drive, operation modes, permanent-magnet (PM) motor drive, proportional-integral (PI) control, torque ripple.

\section{INTRODUCTION}

$\mathbf{T}$ HE doubly salient permanent-magnet (DSPM) motor drive has attracted more and more attention since its advent, due to the definite advantages of simple structure, high power density, high efficiency, etc. [1]-[7]. There is a wide range of possible combinations of phase windings and stator and rotor pole numbers that can be chosen for a DSPM motor design. In accordance with the basic operation principle of the DSPM motor, the general relationships among $p_{s}, p_{r}$ and $m$ are given by

$$
\left\{\begin{array}{l}
p_{s}=2 m k \\
p_{r}=p_{s} \pm 2 k
\end{array}\right.
$$

where $p_{s}$ and $p_{r}$ are the number of stator and rotor poles, respectively, $m$ is the number of phases, and $k$ is a positive in-

Paper IPCSD 03-075, presented at the 2002 Industry Applications Society Annual Meeting, Pittsburgh, PA, October 13-18, and approved for publication in the IEEE TRANSACTIONS ON INDUSTRY APPLICATIONS by the Industrial Drives Committee of the IEEE Industry Applications Society. Manuscript submitted for review November 1, 2002 and released for publication June 7, 2003. This work was supported in part by a grant from the Ministry of Education of China, by a grant from the Science Foundation of Southeast University, China, and by a grant from the RGC Project HKU 7035/01E, Hong Kong.

M. Cheng and Q. Sun are with the Department of Electrical Engineering, Southeast University, Nanjing 210096, China (e-mail: mcheng@seu.edu.cn; sun211@seu.edu.cn).

K. T. Chau and C. C. Chan are with the Department of Electrical and Electronic Engineering, The University of Hong Kong, Hong Kong (e-mail ktchau@eee.hku.hk; ccchan@eee.hku.hk).

Digital Object Identifier 10.1109/TIA.2003.816506 teger. When the motor runs at the speed of $n$, the commutating frequency of any phase is

$$
f_{\mathrm{ph}}=\frac{p_{r} n}{60}
$$

To minimize the switching frequency and, hence, the iron losses in poles and yokes as well as the loss in power switches, the number of rotor poles should be selected as small as possible. Therefore, the number of rotor poles is usually less than that of stator poles.

To make the motor capable of starting itself in either forward or reverse direction, the phase number should be equal to or greater than three. Thus, $p_{s} / p_{r}=6 / 4,8 / 6$, and $12 / 8$ are possible configurations of the DSPM motor. The three-phase 6/4-pole machine has starting torque capability in either direction while keeping the number of switching devices low. In a three-phase 12/8-pole machine [8], although the flux paths are shorter, the fundamental excitation frequency is doubled, which tends to cancel the potential advantage of lower iron loss, especially at high speed. To the best of the authors' knowledge, most of the available literature by other authors has dealt with a three-phase 6/4-pole DSPM motor configuration [1]-[4], [7]. Possible reasons may be due to the impression that the three-phase counterpart is simpler than the four-phase 8/6-pole one in terms of both construction and control.

In [9], an 8/6-pole DSPM motor was proposed and its advantages over a 6/4-pole one, namely, higher power density, wider speed range, less torque ripple and lower current magnitude, were revealed. Then, the design and analysis of this DSPM motor were presented in [10]. The corresponding output power equation was analytically derived. The initial sizing of motor dimensions and parameters, namely, the core diameter, stack length, PM size, and winding turns, were discussed in particular. Moreover, finite-element analysis of this motor, taking into account the iron saturation and the leakage flux outside the stator circumference, was presented. Recently, the split-winding concept was also applied to this DSPM motor, which could significantly extend its constant-power capability at high speeds [11].

The purpose of this paper is to propose and implement the control and operation of the new 8/6-pole DSPM motor drive. In Section II, the basic structure and operating principle of the DSPM motor drive will be described. Section III will be devoted to presenting the control strategy and the main control circuitries. The method of detection for the rotor position and speed will be specifically discussed in Section IV. Then, two operation modes for the 8/6-pole DSPM motor, namely, four-phase and two-phase operation modes, will be proposed in Section V. Section VI will be devoted to presenting the implementation and experiments of a four-phase 8/6-pole DSPM motor drive. Finally, some conclusions will be drawn in Section VII. 


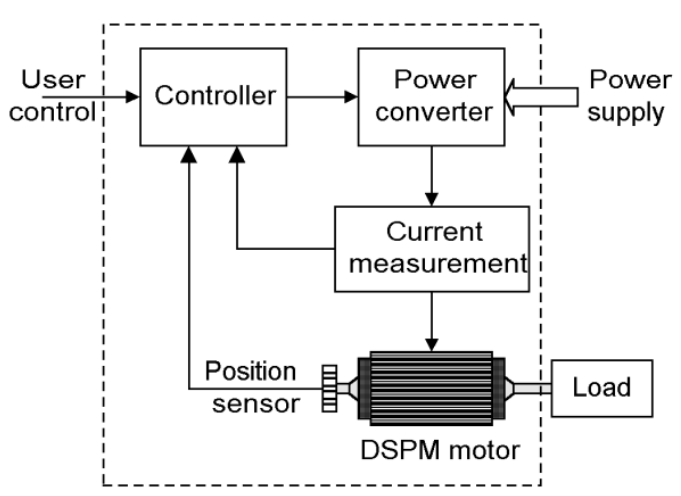

Fig. 1. System configuration of a DSPM motor drive.

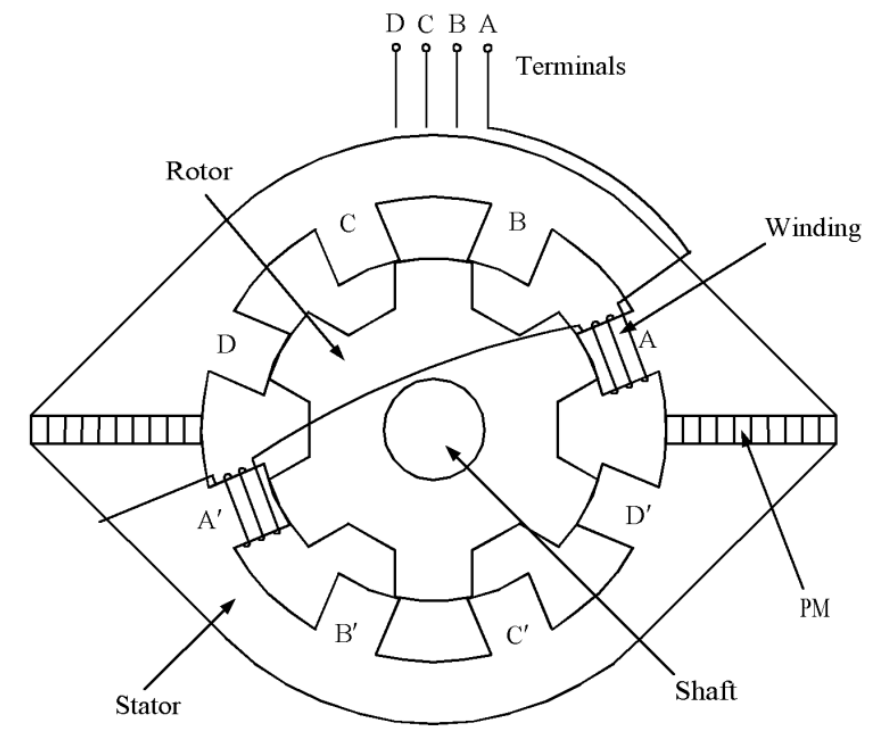

Fig. 2. Cross section of 8/6-pole DSPM motor.

\section{BASIC STRUCTURE AND OPERATION PRINCIPLE}

A DSPM motor drive typically consists of four basic parts: DSPM motor, power converter, rotor position sensor, and controller, as shown in Fig. 1. A DSPM motor essentially adopts the same structure as a switched reluctance (SR) motor but with PMs in the stator, as shown in Fig. 2. It has saliency on both stator and rotor. There is a very simple concentrated coil on each stator pole. Coils wound on the diametrically opposite stator poles, say $\mathrm{A}-\mathrm{A}^{\prime}$, are connected in series or in parallel to constitute a phase winding so that their fluxes are additive when a current flows in them. Obviously, the machine is of simple structure and free of maintenance, and is capable of working at high speed. The corresponding PMs are located in the stator and, thus, can be easily cooled, hence eliminating the problem of irreversible demagnetization and mechanical instability. In addition, since the stator windings are concentrated, the overhanging part of the coil is short, resulting in the saving of copper as well as the reduction of copper loss.

Unlike traditional electric machines, such as induction or dc machines, the DSPM motor cannot directly run from an ac or dc supply. The currents in the stator windings of the DSPM motor

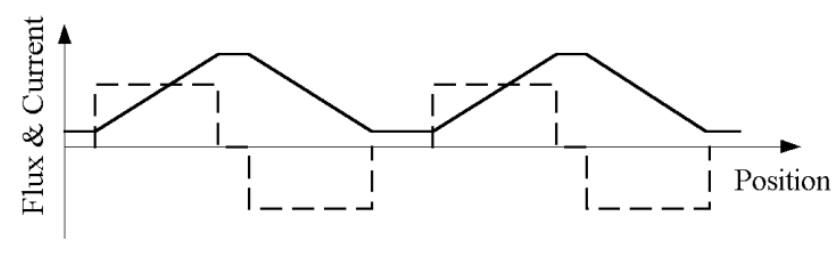

Fig. 3. Theoretical flux (solid) and current (dashed) waveforms.

must be switched on or off in accordance with the rotor positions so as to produce motoring torque. Hence, a power converter and a rotor position sensor are indispensable in the DSPM motor drive. The power converter must also regulate the magnitude of the current to meet the demand of torque and speed placed on the drive by the load. A phase-current measuring device should, therefore, be present.

Ideally, a linear variation of PM flux linkage and, thus, a trapezoidal back electromotive force (EMF) are induced in each of the stator windings at no load under the assumptions that the fringing is negligible and the permeability of the core is infinite. The corresponding theoretical waveforms of PM flux and phase current for one phase are shown in Fig. 3. When the machine is loaded, the armature reaction flux is produced in addition to the PM flux. It is important to note, however, that the existence of the PMs constitutes a very high reluctance path for the armature reaction flux and thus forces the bulk of the armature reaction flux to circulate through the other overlapping pole pairs. As a result, the inductance of the phase winding is small at both aligned and unaligned positions. In contrast to the SR motor, this small aligned inductance makes it possible to reverse the current rapidly at the aligned position.

The electromagnetic torque for one-phase-on operation of a DSPM motor can be derived as [10]

$$
T_{e}=\frac{1}{2} i_{s}^{2} \frac{d L}{d \theta}+i_{s} \frac{d \psi_{\mathrm{pm}}}{d \theta}=T_{r}+T_{\mathrm{pm}}
$$

where $T_{r}=(1 / 2) i_{s}^{2}(d L / d \theta)$ is the reluctance torque component due to the variation of inductance, $T_{\mathrm{pm}}=i_{s}\left(d \psi_{\mathrm{pm}} / d \theta\right)$ is the PM torque component due to the interaction between the PM flux linkage and the armature current, $L$ is the inductance of phase winding, $\psi_{\mathrm{pm}}$ is the PM flux linkage, $i_{s}$ is the phase current, and $\theta$ is the rotor position angle. Because of symmetry of the inductance characteristics, the average value of reluctance torque is near zero. Hence, the PM torque is the dominant component in the DSPM motor. It can be seen from the expression of the PM torque that unidirectional torque can be achieved both by applying a positive current to the winding when its PM flux is increasing with rotor position and by applying a negative current when the PM flux is decreasing. Thus, the two possible torque-producing zones are all utilized.

\section{CONTROL STRATEGY}

The speed of the DSPM motor drive is controlled by a closed-loop digital proportional-integral (PI) controller whose output is the torque reference $T^{*}$. Fig. 4 shows a block diagram of the speed control system, which includes a model of DSPM motor, a load, and a PI regulator performed by microcontroller. 


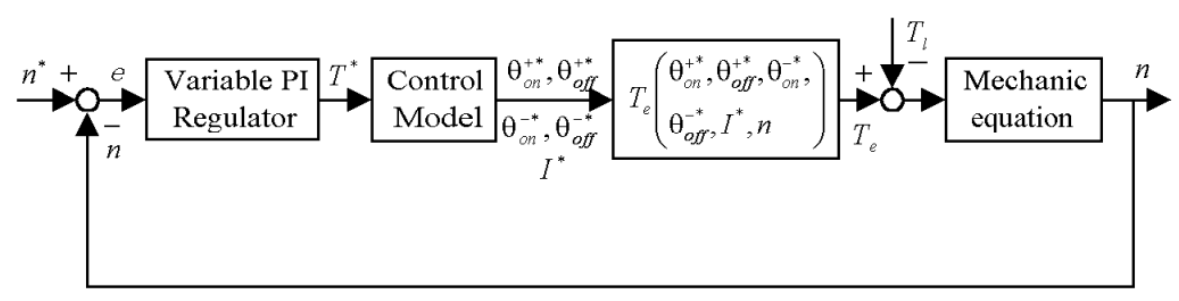

Fig. 4. Control of DSPM motor drive.

The discrete equation for a digital PI controller can be obtained as [12]

$$
T^{*}(k)=k_{p} e(k)+k_{i} \sum_{j=0}^{k} e(j)
$$

where $e(k)$ is the speed error, and $k_{p}$ and $k_{I}$ are the proportional and integral gains, respectively. The selection of the controller means finding a compromise between the requirement for fast control and the need for stable control. It is found that to tune one set of PI parameters satisfying whole speed and load range is difficult, due to the fact that the motor parameters, such as phase inductance, vary with both the load current and rotor position [10] and, hence, for the given control parameters of switching angles $\theta_{\text {on }}^{+}, \theta_{\text {off }}^{+}, \theta_{\text {on }}^{-}, \theta_{\text {off }}^{-}$, and current $I$, the motor may produce different torque at different load conditions and speeds. This implies that the produced torque $T_{e}$ may not track the torque command $T^{*}$. Therefore, the adaptive proportional and integral gains are required, which are defined, respectively, as

$$
\begin{aligned}
k_{p} & =a_{p}+b_{p}(e(t))^{2} \\
k_{i} & =\frac{a_{i}}{1+b_{i}(e(t))^{2}}
\end{aligned}
$$

where $a_{p}, b_{p}, a_{i}$, and $b_{i}$ are nonnegative real numbers. Substituting (5) and (6) into (4) yields

$$
T^{*}(k)=\left[a_{p}+b_{p}(e(k))^{2}\right] e(k)+\frac{a_{i}}{1+b_{i}(e(k))^{2}} \sum_{j=0}^{k} e(j) .
$$

Noting that when $b_{p}$ and $b_{i}$ are set to be zero, (7) retrogresses to the normal linear PI controller.

To reduce the frequency of speed regulation, a small dead zone of speed is deliberately introduced into the controller. That is, when the speed error is less than $\varepsilon_{1}$, the output of the controller $T(k)$ takes the previous value $T(k-1)$ without corrective actions.

To speed up the dynamic response, the bang-bang control is combined with the PI control. When the absolute value of the speed error is larger than a predefined value $\varepsilon_{2}$, the bang-bang control is adopted. Otherwise, PI control is performed

$$
\left\{\begin{array}{l}
e(k)>\varepsilon_{2} \cdots \text { bang-bang control } \\
e(k) \leq \varepsilon_{2} \cdots \text { PI control. }
\end{array}\right.
$$

In bang-bang control, if the speed error is positive and the speed is increasing, the output of the controller is directly set to be the maximum. Otherwise, it is set to be zero (due to the fact that the dc-bus voltage is fed from the ac power supply via a diode rectifier and it does not allow reversing the direction of dc current, leading to an absence of negative or braking torque).

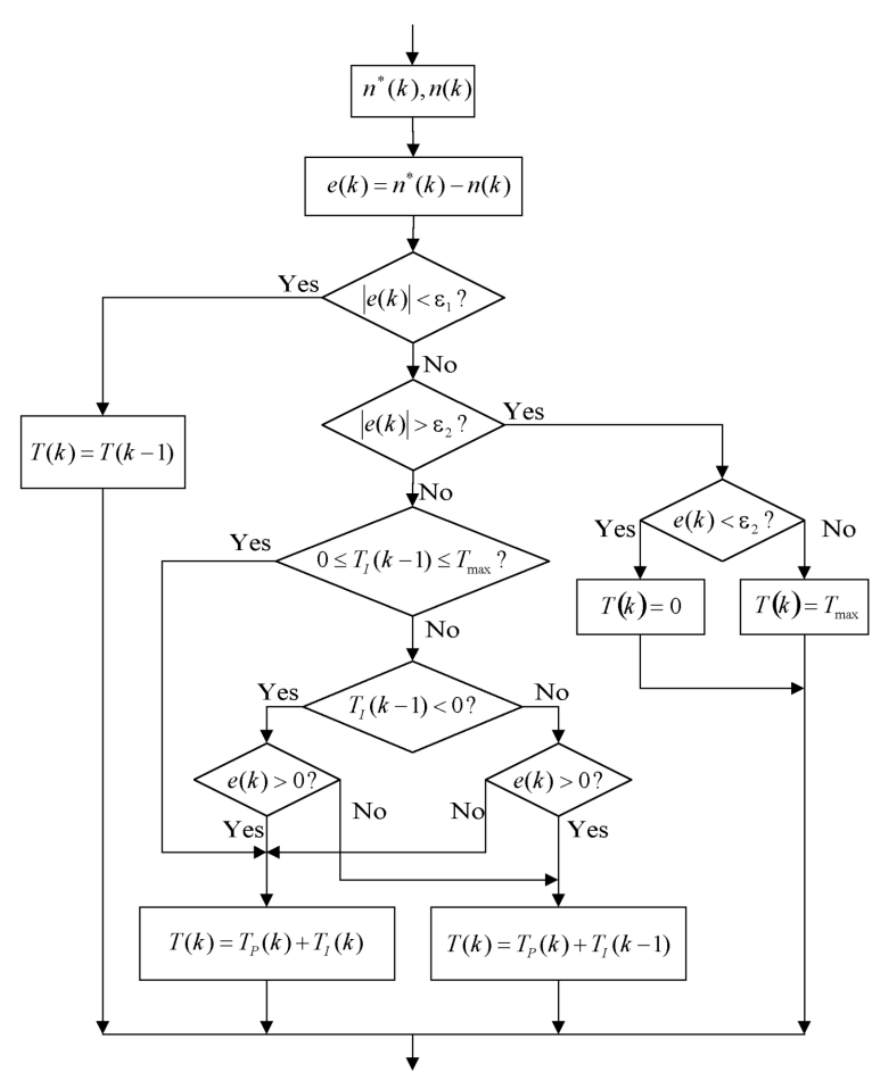

Fig. 5. Structure of the digital PI controller.

The structure of the developed PI controller for the DSPM motor drive is shown in Fig. 5.

In the DSPM motor, four angles, namely, $\theta_{\mathrm{on}}^{+}, \theta_{\mathrm{off}}^{+}, \theta_{\mathrm{on}}^{-}$, and $\theta_{\text {off }}^{-}$, as well as current reference $I^{*}$ are possible control variables to shape the phase current, which can give a very complicated control schemes. However, a simple but efficient control strategy is developed. When the speed is below the base speed, current-chopping control (CCC) is adopted for the constant torque operation, in which the four angles are fixed and the torque is controlled by current reference $I^{*}$. Since the current waveforms in the positive and negative strokes are symmetrical in CCC mode, the average value of reluctance torque component is zero. Thus, the average torque of the motor is governed by the PM torque component only, which is given by

$$
T_{a v}=\frac{2 m}{\theta_{c r}} \int_{\theta_{\mathrm{on}}^{+}}^{\theta_{\mathrm{off}}^{+}}\left(I \frac{d \psi_{\mathrm{pm}}}{d \theta}\right) d \theta \approx \frac{2 m}{\theta_{c r}} I\left(\psi_{\mathrm{pm} 2}-\psi_{\mathrm{pm} 1}\right)
$$




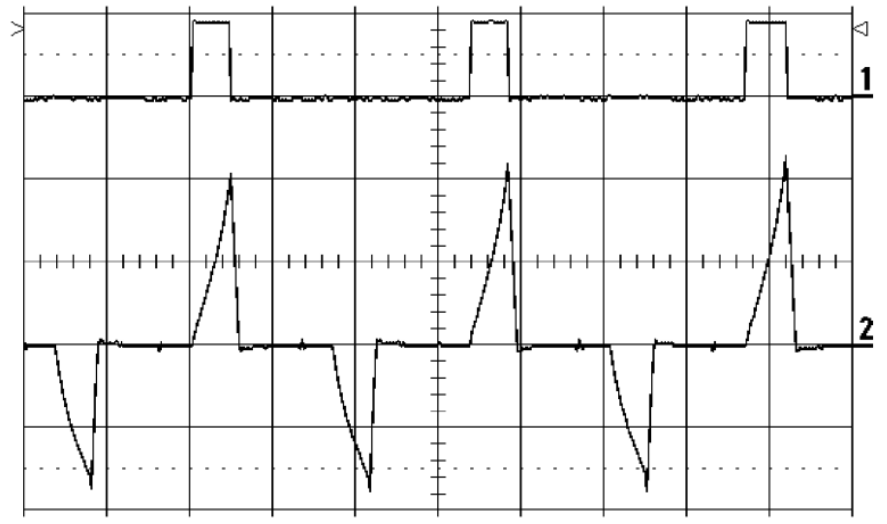

Fig. 6. Measured phase current (lower trace) and positive stroke firing signal (upper trace) waveforms at APC mode with light load.

where $I$ is the magnitude of the rectangular current, $m$ the phase number, $\theta_{c r}$ the rotor pole pitch angle, $\psi_{\mathrm{pm} 1}$ and $\psi_{\mathrm{pm} 2}$ are the PM flux linkages corresponding to $\theta_{\mathrm{on}}^{+}$and $\theta_{\text {off }}^{+}$, respectively. It is seen that the average torque is proportional to the current $I$. Hence, once the torque reference $T^{*}$ is obtained by using PI regulation, the current reference $I^{*}$ can readily be specified using (9).

When the speed is above the base speed, the angle position control (APC) is performed for the constant power operation. In this high speed APC mode, the torque is controlled by the conduction angle $\theta_{w}$, which is given by

$$
\theta_{w}=\theta_{\text {off }}^{+}-\theta_{\text {on }}^{+}=\theta_{\text {off }}^{-}-\theta_{\text {on }}^{-} \text {. }
$$

The relation between the torque and conduction angle is nonlinear and complex. It is difficult to get a definite expression between the torque and conduction angle because the current waveform at APC mode is not as regular as that at CCC mode. However, one can get their relations at some operation points by steady-state simulation and fits them a polynomial as

$$
\theta_{w}=f\left[T^{*}(k), n(k-1)\right] .
$$

Fig. 6 illustrates the measured current waveform of the motor with a light load at the APC mode.

To perform the CCC, the phase current is measured by an LEM module and is fed back to a hysteresis controller. To simplify the comparison of the measured current with the current reference, an absolute value amplifier is adopted to convert the ac phase current of the DSPM motor to dc current for each phase. Fig. 7 illustrates the circuitry of the absolute value amplifier and the comparison between the input and output signals of the amplifier at a $20-\mathrm{kHz}$ sinusoidal waveform input, showing a very small distortion.

\section{Detection of Rotor Position ANd SPEed}

In accordance with the operation principle of the DSPM motor, the phase winding should be turned on or off at the specific rotor positions. Hence the rotor position information is indispensable for the proper operation of the DSPM motor. For the motor drive system developed in this paper, positions are measured by a simple position sensor (PS). As shown in Fig. 8, this PS consists of a slotted disc connected to the rotor shaft

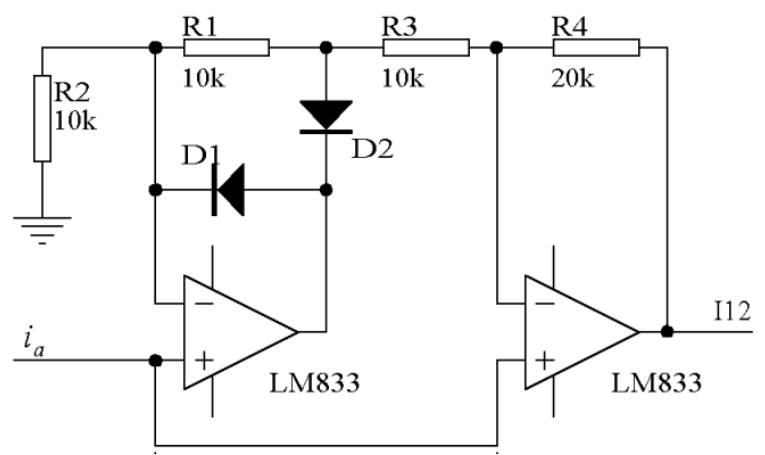

(a)
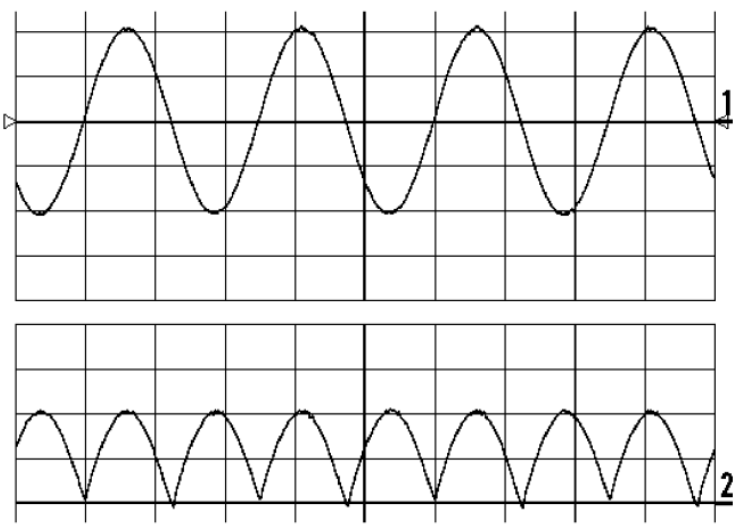

(b)

Fig. 7. Absolute value amplifier. (a) Circuitry. (b) Input (upper trace) and output (lower trace) waveforms at $20 \mathrm{kHz}$.

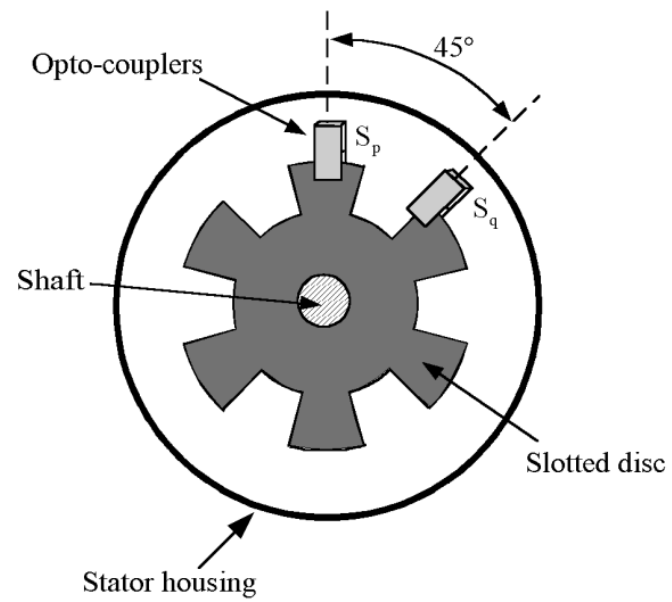

Fig. 8. Position sensor.

and two optocouplers mounted to the stator housing. The two optocouplers are nominally located $45^{\circ}$ apart from each other along the circumference of the disc. The output waveforms of the sensor are shown in Fig. 9. The sensor generates a signal edge for every $15^{\circ}$ of mechanical rotation. The transitions of these outputs determine specific angles. At each edge, the speed is estimated by

$$
\hat{n}=\frac{60 \Delta r}{\Delta t}=\frac{f_{\text {clk }}}{0.4 N}
$$

where $\hat{n}$ is the estimated speed in revolutions per minute, $\Delta r$ the distance between edges in revolution, $\Delta t$ the time between 


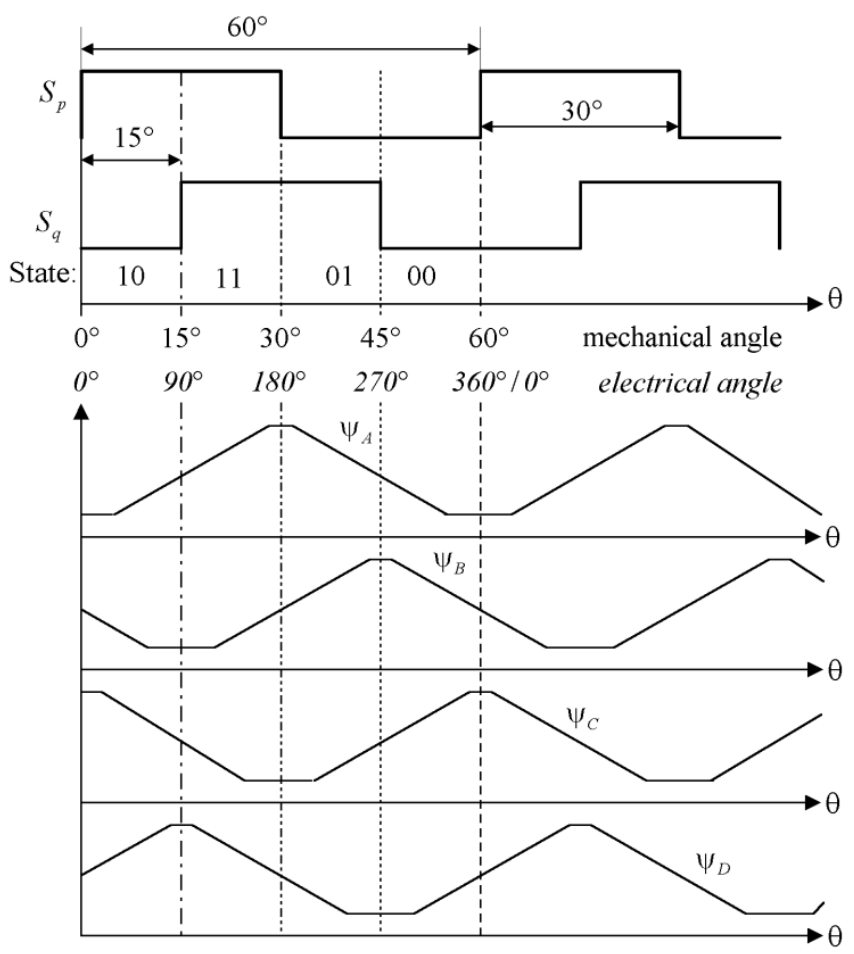

Fig. 9. Position signals $S_{p}$ and $S_{q}$ and PM flux linkages $\psi_{A}-\psi_{D}$.

edges, $N$ the number of clock counts between edges, and $f_{\text {clk }}$ the clock frequency.

For the proposed four-phase 8/6-pole DSPM motor, the control logic can be obtained as given in Table I according to the relationship between the PM fluxes and position signals in Fig. 9.

\section{OPERATION MODES OF 8/6-POLE DSPM Motor Drive}

\section{A. Four-Phase Operation}

To supply the DSPM motor, a bipolar converter is preferred so as to bring the merit of the DSPM motor into full play. To control the phase currents individually, there are basically two inverter topologies possible for bidirectional operation of the DSPM motor, namely, the full-bridge inverter, and the half-bridge inverter with split capacitors [13]. The latter topology is usually selected for the DSPM drive system, because it minimizes the use of power devices, as shown in Fig. 10.

For three-phase 6/4-pole DSPM motors, the connection between the centerpoint of the split capacitors and the neutral of motor windings, as shown by the dotted line in Fig. 10, is usually necessary to accommodate the additional current during the commutation period. However, voltage asymmetry between the two split capacitors often occurs because of the asymmetry of phase currents in the DSPM motor [2]. As a result, different voltages are applied to the upper and lower legs, which degrades the dynamic behavior of the motor drive, increases the torque ripple, and even damages the capacitors and the control system. Therefore, some auxiliary hardware and software are necessary to keep the voltage at the centerpoint of the capacitors almost constant, which makes the control system more complicated.

For the proposed four-phase 8/6-pole DSPM motor, however, it can be found from the control logic given in Table I that at any

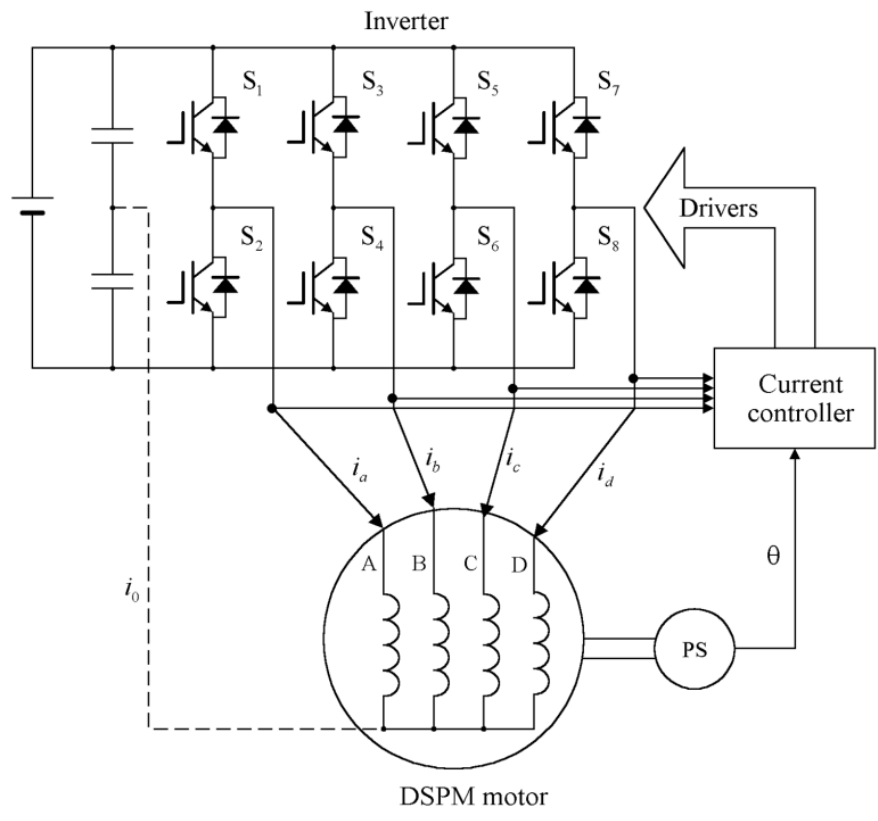

Fig. 10. Schematic connection between DSPM motor and inverter.

TABLE I

CONTROL LOGIC OF 8/6-POLE DSPM Motor Drive

\begin{tabular}{c|c|cccc}
\hline \multicolumn{2}{c|}{ Signal states: $\mathrm{S}_{\mathrm{p}} \mathrm{S}_{\mathrm{q}}$} & 00 & 01 & 10 & 11 \\
\hline \multirow{2}{*}{ Phase A } & $\mathrm{S}_{1}$ & 0 & 0 & 1 & 1 \\
& $\mathrm{~S}_{2}$ & 1 & 1 & 0 & 0 \\
\hline \multirow{2}{*}{ Phase B } & $\mathrm{S}_{3}$ & 0 & 1 & 0 & 1 \\
& $\mathrm{~S}_{4}$ & 1 & 0 & 1 & 0 \\
\hline \multirow{2}{*}{ Phase C } & $\mathrm{S}_{5}$ & 1 & 1 & 0 & 0 \\
& $\mathrm{~S}_{6}$ & 0 & 0 & 1 & 1 \\
\hline \multirow{2}{*}{ Phase D } & $\mathrm{S}_{7}$ & 1 & 0 & 1 & 0 \\
& $\mathrm{~S}_{8}$ & 0 & 1 & 0 & 1 \\
\hline
\end{tabular}

time instant the power switches in upper and lower legs of the inverter are conducting in pairs (phase $A$ pairs up with phase $C$, and phase $B$ pairs up with phase $D$ ). Hence, it arises the possibility of removing the connection between the centerpoint of the split capacitors and the neutral of the motor windings without significant influence on the behavior of the motor drive provided $\theta_{\mathrm{on}}^{-}=\theta_{\mathrm{on}}^{+}+(1 / 2) \theta_{c r}$ and $\theta_{\mathrm{off}}^{-}=\theta_{\mathrm{off}}^{+}+(1 / 2) \theta_{c r}$. As a consequence, the problem of voltage unbalance in the split capacitors is eliminated and the hardware and software of the control system are thus simplified. Moreover, because the positive half cycle and negative half cycle of the phase current are forced to be almost symmetrical, the average value of the reluctance torque approaches zero, minimizing torque ripple.

\section{B. Two-Phase Operation}

Further inspecting the characteristics and the control logic of the 8/6-pole DSPM motor drive reveals that there is a possibility of the DSPM motor working as a two-phase motor drive. Reversibly connecting the winding $A$ with $C$ and winding $B$ with $D$, respectively, in series, as shown in Fig. 11, we can construct a two-phase DSPM motor drive. It can be supplied by a two-phase full-bridge inverter or a half-bridge inverter with split capacitors. In the former case, the dc-bus voltage and the number of 


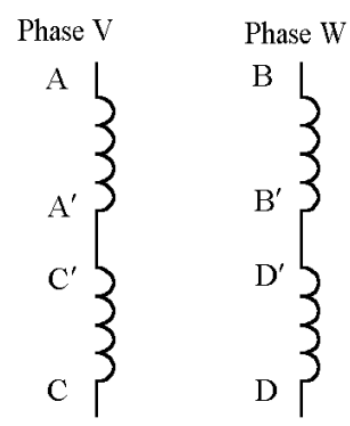

Fig. 11. Winding connection of two-phase operation mode of 8/6-pole DSPM motor.

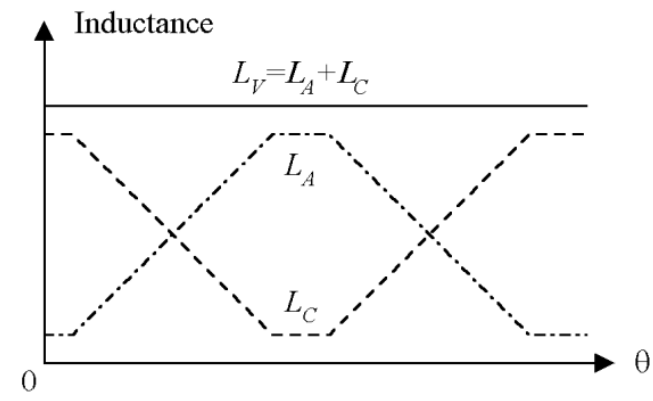

Fig. 12. Theoretical self-inductance.

power switches are the same as those in the four-phase operation mode with the half-bridge inverter in Fig. 10. In the latter case, however, the dc-bus voltage and in turn the voltage rating of power switches are doubled though the number of power switches is halved. Hence, the full-bridge inverter is preferable.

What is more important is that the two-phase operation mode offers the possibility of eliminating the torque ripple of the motor drive. First, the self-inductance of each phase in two-phase mode should be equal to the summation of Phases $A$ and $C$ or Phases $B$ and $D$ as given by

$$
L_{V}(\theta)=L_{A}(\theta)+L_{C}(\theta) .
$$

As shown in Fig. 12, because of the inverse characteristics of $L_{A}(\theta)$ and $L_{C}(\theta), L_{V}(\theta)$ remains constant. Thus, according to (3), the reluctance torque is always zero.

Secondly, to minimize the cogging torque of the DSPM motor, the rotor is skewed by an appropriate angle. In this case, the back EMF of the DSPM motor is very close to sinusoidal waveform as shown in Fig. 13. Assuming that the back EMF of Phase $V$ can be expressed as

$$
e_{V}=E_{m} \sin \theta \text {. }
$$

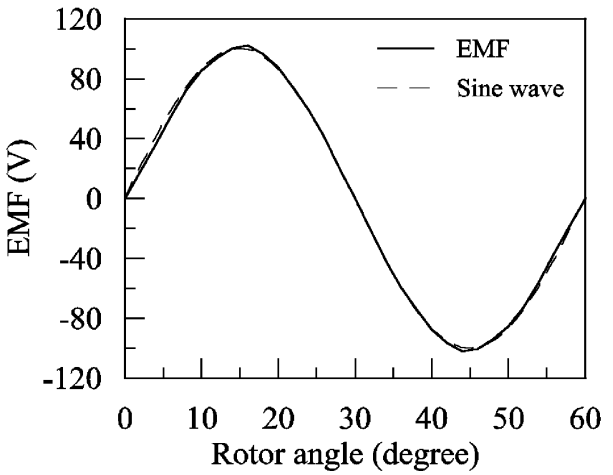

Fig. 13. Comparison between back EMF and sine wave.

Then the back EMF of Phase $W$ can be obtained by lagging $90^{\circ}$ electrical angle as

$$
e_{W}=E_{m} \sin \left(\theta-90^{\circ}\right) .
$$

If sinusoidal currents in phase with the back EMFs are properly applied to the phase windings by appropriate control strategy, the PM torque components can be obtained as

$$
\begin{aligned}
T_{\mathrm{pm} V} & =\frac{e_{V} i_{V}}{\omega_{r}} \\
& =\frac{E_{m} I_{m}}{\omega_{r}} \sin ^{2} \theta \\
& =T_{m} \sin ^{2} \theta \\
T_{\mathrm{pm} W} & =\frac{e_{W} i_{W}}{\omega_{r}} \\
& =\frac{E_{m} I_{m}}{\omega_{r}} \sin ^{2}\left(\theta-90^{\circ}\right) \\
& =T_{m} \sin ^{2}\left(\theta-90^{\circ}\right)
\end{aligned}
$$

where $T_{m}=E_{m} I_{m} / \omega_{r}$ is the magnitude of torque, and $\omega_{r}$ is the angular velocity of the motor. Then, the total electromagnetic torque is

$$
\begin{aligned}
T_{e} & =T_{\mathrm{pm} V}+T_{\mathrm{pm} W} \\
& =T_{m}\left[\sin ^{2} \theta+\sin ^{2}\left(\theta-90^{\circ}\right)\right] \\
& =T_{m}\left[\frac{1-\cos (2 \theta)}{2}+\frac{1-\cos \left(2 \theta-180^{\circ}\right)}{2}\right] \\
& =T_{m}\left[1-\frac{\cos (2 \theta)+\cos \left(180^{\circ}-2 \theta\right)}{2}\right] \\
& =T_{m} .
\end{aligned}
$$

Equation (18) indicates that the total electromagnetic torque does not vary with rotor position and keeps constant, as shown in Fig. 14. This suggests that the DSPM motor drive is able to compete against the traditional motor drives not only in simple structure, high power density, and fast response, but also in the smoothness of torque characteristic. 


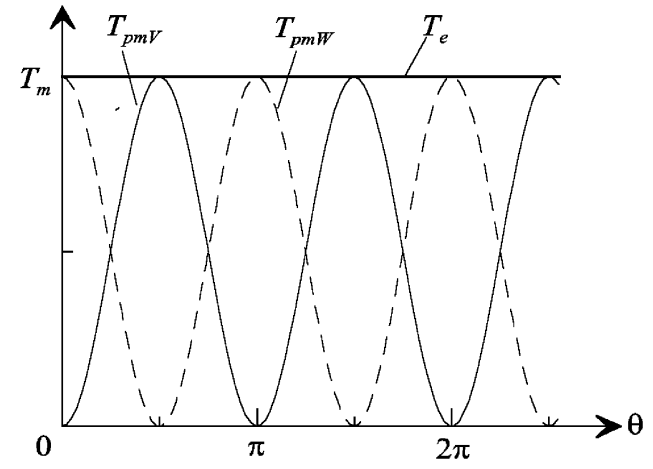

Fig. 14. Summation of two torque components.

TABLE II MOTOR PARAMETERS

\begin{tabular}{l|l}
\hline Rated power $(\mathrm{W})$ & 750 \\
Rated phase voltage $(\mathrm{V})$ & 200 \\
Rated speed $(\mathrm{r} / \mathrm{min})$ & 1500 \\
Phase number & 4 \\
Stator pole number & 8 \\
Rotor pole number & 6 \\
Stator inner diameter $(\mathrm{mm})$ & 75 \\
Stator pole width $(\mathrm{mm})$ & 14.4 \\
Stator pole height $(\mathrm{mm})$ & 13 \\
Rotor pole width $(\mathrm{mm})$ & 16.8 \\
Rotor pole height $(\mathrm{mm})$ & 10 \\
Stack length $(\mathrm{mm})$ & 75 \\
Airgap length $(\mathrm{mm})$ & 0.45 \\
Winding turns per phase & 220 \\
Magnet remanence $(\mathrm{T})$ & 1.08 \\
Magnet coercive force $(\mathrm{kA} / \mathrm{m})$ & 843.5 \\
Magnet dimensions $(\mathrm{mm})$ & $75 \times 37 \times 6$ \\
\hline
\end{tabular}

It should be noted that although the phase inductance in twophase mode is higher than that in four-phase mode, the electrical time constant of the motor in two-phase operation is equal to or even less than that in four-phase operation due to the fact that the phase resistance is doubled in two-phase operation as compared with the four-phase operation mode.

\section{IMPLEMENTATION AND RESULTS}

An experimental 8/6-pole DSPM motor drive with the ratings of $750 \mathrm{~W}$ and $1500 \mathrm{r} / \mathrm{min}$ has been designed and built for verification. The main design data are given in Table II. An insulated-gate-bipolar-transistor (IGBT)-based four-phase inverter and a microcomputer-based digital controller are designed and implemented to drive the motor. A dc dynamometer was used as variable load. The current and input power of the DSPM motor were measured by a digital power analyzer. Fig. 15 shows a photograph of the test set.

Both the steady-state and dynamic operation performance were tested. Fig. 16 shows the measured current waveforms at CCC and APC modes, respectively. Fig. 17 depicts the measured efficiency of the motor at the rated speed of $1500 \mathrm{r} / \mathrm{min}$. It is seen that the motor offers high efficiency over wide output power range, which is highly desirable for some applications such as electric vehicles. The efficiency at the rated operating point is $87.7 \%$, much higher than that of a standard induction motor (typically, 75\%) with the same capacity and speed.

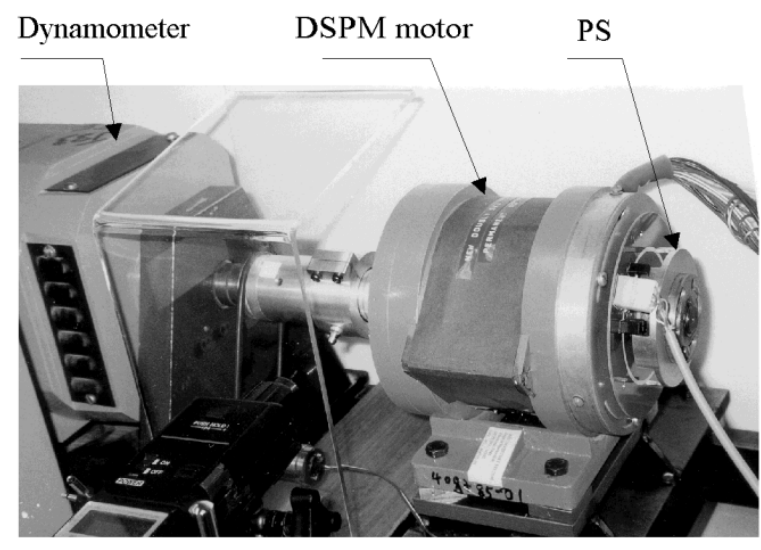

Fig. 15. Test set of the DSPM motor drive.

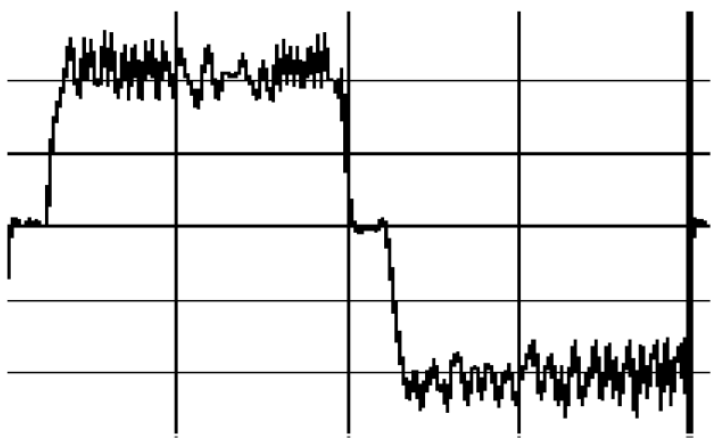

(a)

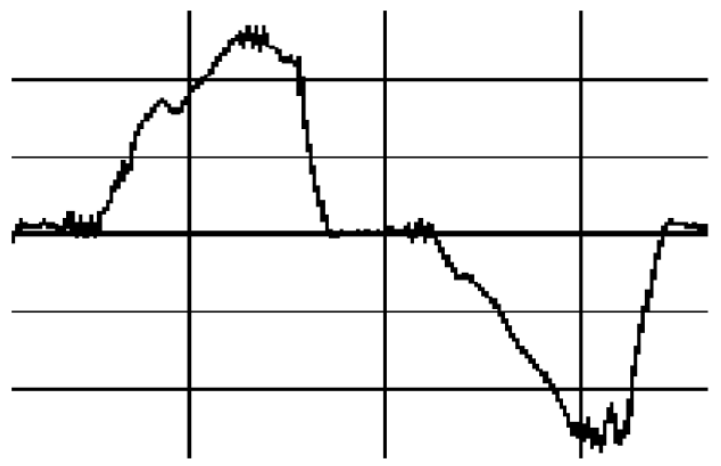

(b)

Fig. 16. Current waveforms at steady-state operation. (a) CCC mode. (b) APC mode.

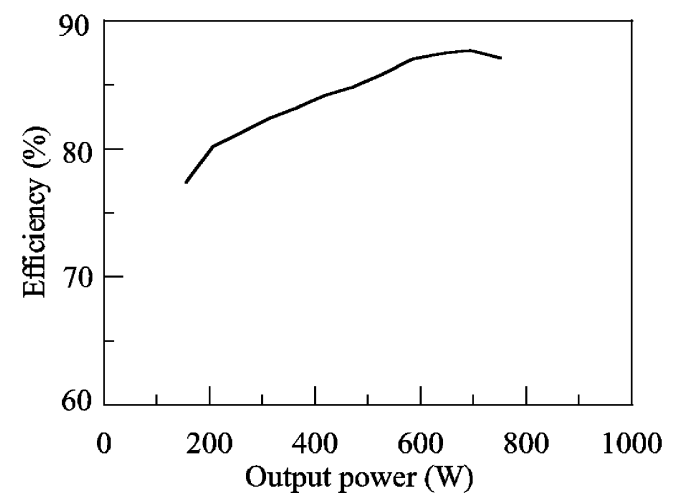

Fig. 17. Measured efficiency at $1500 \mathrm{r} / \mathrm{min}$. 


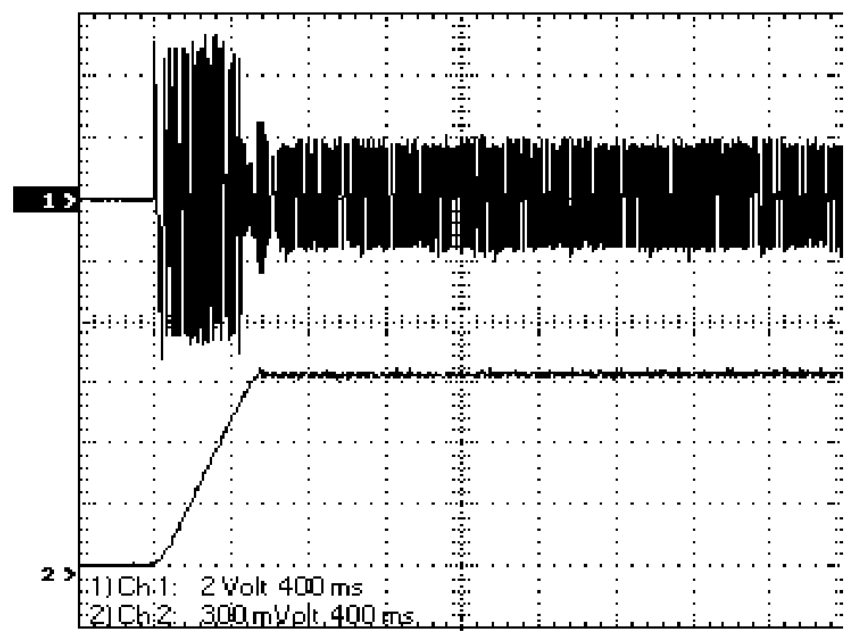

Fig. 18. Measured current (upper trace) and speed (lower trace) responses at starting $(2.5 \mathrm{~A} / \mathrm{div}, 400 \mathrm{r} / \mathrm{min} / \mathrm{div}, 0.4 \mathrm{~s} / \mathrm{div})$.

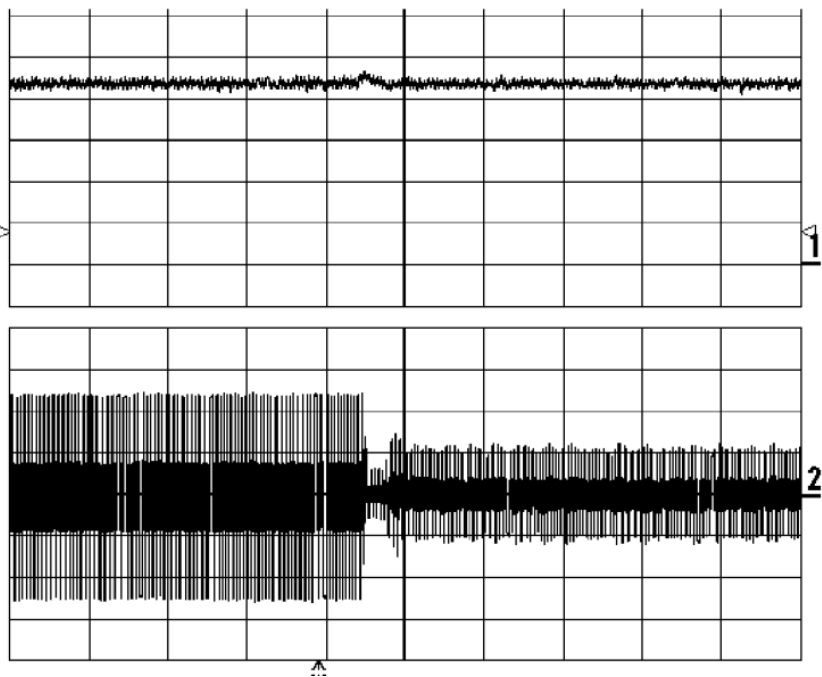

Fig. 19. Measured speed (upper trace) and current (lower trace) responses at sudden change of load at $1500 \mathrm{r} / \mathrm{min}(350 \mathrm{r} / \mathrm{min} / \mathrm{div}, 2 \mathrm{~A} / \mathrm{div}, 0.5 \mathrm{~s} / \mathrm{div})$.

To verify the dynamic performance of the motor drive, the transient responses of speed and current are recorded by an oscilloscope. Fig. 18 shows the starting response from standstill to the speed of $1200 \mathrm{r} / \mathrm{min}$. It can be seen that the motor drive responds quickly and there is almost no overshoot. The steadystate error of speed is less than $2 \mathrm{r} / \mathrm{min}$. Moreover, Fig. 19 gives the dynamic responses of speed and current under a sudden change of load torque from 2.66 to $0.66 \mathrm{~N} \cdot \mathrm{m}$ at the rated speed of $1500 \mathrm{r} / \mathrm{min}$. It can be found that the transient rise in speed is very small and the speed regulation of the motor drive is good, illustrating that the developed variable PI controller is effective.

The research on the two-phase operation mode of the proposed 8/6-pole DSPM motor drive is under way and the experimental results will be reported in a separate paper in the near future.

\section{CONCLUSION}

This paper has proposed a new 8/6-pole DSPM motor drive. The control strategy of the motor drive has been developed and a digital variable PI controller combined with bang-bang control has been specified. A digital control system for the motor drive has been developed based on a 16-bit high-speed microcomputer. According to the unique features of the proposed 8/6-pole DSPM motor, two operation modes, namely, four-phase operation and two-phase operation, have been proposed to operate the motor. A prototype drive system with four-phase operation mode has been designed, implemented, and tested. The results show that the developed control scheme can operate the DSPM motor properly. The proposed 8/6-pole DSPM motor drive offers the advantages of high efficiency over a wide power range and good dynamic response. Moreover, the two-phase operation mode of the 8/6-pole DSPM motor offers the possibility of eliminating the torque ripple of the DSPM motor drive while keeping the same (even less) electrical time constant, same supply voltage, and same number of power device as those of the four-phase operation mode. Therefore, the developed 8/6-pole DSPM motor drive is able to compete against the traditional motor drives not only in simple structure, high power density, high efficiency and fast response, but also in the smoothness of torque characteristic.

\section{REFERENCES}

[1] Y. Liao, F. Liang, and T. A. Lipo, "A novel permanent magnet motor with doubly salient structure," IEEE Trans. Ind. Applicat., vol. 31, pp. 1069-1078, Sept./Oct. 1995.

[2] F. Blaabjerg, L. Christensen, P. O. Rasmussen, L. Oestergaard, and P. Pedersen, "New advanced control methods for doubly salient permanent magnet motor," in Conf. Rec. IEEE-IAS Annu. Meeting, Orlando, FL, 1995, pp. 222-230.

[3] J. Yuan and K. D. Zhou, "Simulation and analysis on influence of permanent-magnet for doubly salient permanent magnet motor system," in Proc. Fourth Int. Conf. Electromagnetic Field Problems and Applications, Tianjin, China, Sept. 18-20, 2000, pp. 322-324.

[4] C. Martis, M. M. Radulescu, and K. Biro, "On the dynamic model of a doubly-salient permanent magnet motor," in Proc. IEEE Mediterranean Electrotechnical Conf., Tel-Aviv, Israel, May 18-20, 1998, pp. 410-414.

[5] D. Bian and Q. Zhan, "A novel single phase doubly salient permanent magnet motor," in Proc. IEEE Int. Conf. Power Electronics and Drive Systems, Hong Kong, 1999, pp. 725-729.

[6] M. Cheng, K. T. Chau, C. C. Chan, E. Zhou, and X. Huang, "Nonlinear varying-network magnetic circuit analysis for doubly salient permanent magnet motors," IEEE Trans. Magn., vol. 36, pp. 339-348, Jan. 2000.

[7] M. M. Radulescu, C. Martis, and I. Husain, "Design and performance of a small doubly-salient rotor-permanent-magnet motor," Elect. Power Comp. Syst., vol. 30, no. 8, pp. 823-832, Aug. 2002.

[8] M. Cheng, K. T. Chau, and C. C. Chan, "Design and analysis of 12/8-pole doubly salient permanent magnet machine," in Proc. IEEE 13th Conf. Computation of Electromagnetic Fields, vol. 1, Lyon-Evian, France, July 2-5, 2001, pp. 166-167.

[9] K. T. Chau, M. Cheng, and C. C. Chan, "Performance analysis of 8/6-pole doubly salient permanent magnet motor," Elect. Mach. Power Syst., vol. 27, no. 10, pp. 1055-1067, Oct. 1999.

[10] M. Cheng, K. T. Chau, and C. C. Chan, "Design and analysis of a new doubly salient permanent magnet motor," IEEE Trans. Magn., vol. 37, pp. 3012-3020, July 2001.

[11] - "New split-winding doubly salient permanent magnet motor drive," IEEE Trans. Aerosp. Electron. Syst., vol. 39, pp. 202-210, Jan. 2003.

[12] K. K. Tan, Q. G. Wang, and C. C. Hang, Advances in PID Control. London, U.K.: Springer, 1999.

[13] N. Mohan, T. M. Undeland, and W. P. Robbins, Power Electronics. New York: Wiley, 1995, pp. 211-212. 


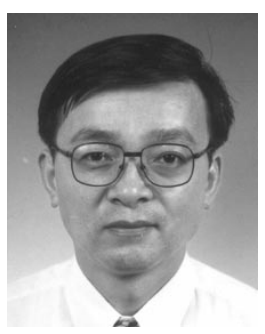

Ming Cheng (M'01-SM'02) received the B.Sc. (Eng.) and M.Sc. (Eng.) degrees from the Department of Electrical Engineering, Southeast University, Nanjing, China, in 1982 and 1987, respectively, and the Ph.D. degree from the Department of Electrical and Electronic Engineering, The University of Hong Kong, Hong Kong, in 2001.

Since 1987, he has been with Southeast University, where he is currently the Dean and a Professor of the Department of Electrical Engineering. His teaching and research interests include electrical machines, motor drives, and power electronics. He has authored over 50 published technical papers and is the holder of five patents in these areas.

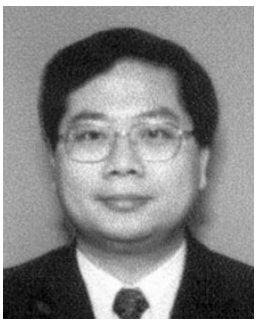

K. T. Chau (M'89) received the first-class honor B.Sc. (Eng.), M.Phil., and Ph.D. degrees in electrical and electronic engineering from The University of Hong Kong, Hong Kong, in 1988, 1991, and 1993, respectively.

He is currently an Associate Professor at The University of Hong Kong. His teaching and research interests focus on three main areas: power converters, machines and drives, and electric vehicles. In these areas, he has authored over 100 published refereed technical papers and many industrial reports. He is the coauthor of a monograph, Modern Electric Vehicle Technology (London, U.K.: Oxford Univ. Press, 2001).

Dr. Chau has served as Chair and Organizing Committee Member for many international conferences.

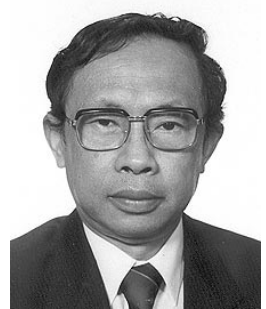

C. C. Chan (M'77-SM'77-F'92) received the B.Sc. degree from China University of Mining and Technology, Beijing, China, in 1953, the M.Sc. degree from Tsinghua University, Beijing, China, in 1957, and the Ph.D. degree from The University of Hong Kong, Hong Kong, in 1981.

$\mathrm{He}$ is currently an Honorary Professor in the Department of Electrical and Electronic Engineering, The University of Hong Kong. He has authored four books, over 120 published technical papers, and is the holder of seven patents.

Prof. Chan is a Fellow of the Royal Academy of Engineering, U.K., an Academician of the Chinese Academy of Engineering, and a Fellow of the Ukraine Academy of Engineering Science. He was awarded the Honorary D.Sc. degree from the University of Odessa in 1992.

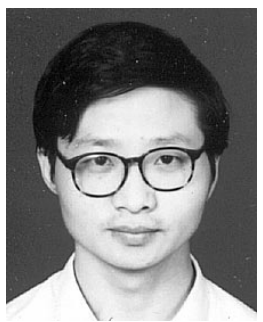

Qiang Sun was born in Anhui Province, China. He received the B.Sc. degree in electrical engineering in 1991 from Hefei University of Technology, Hefei, China, and the M.Sc. (Eng.) degree in electrical engineering in 1999 from Southeast University, Nanjing, China, where he is currently working toward the Ph.D. degree.

His areas of interest include electrical machines and drives, intelligent control, and power electronics. $\mathrm{He}$ has authored five published papers on these topics. 